\title{
Constraints affecting growth of dairying under mixed farming systems : Scientists perception
}

\author{
RACHNA, GAUTAM, ANIKA MALIK AND S. S. SANGWAN
}

Author for Corresponding -

\section{ANIKA MALIK}

Department of Veterinary and Animal Husbandry Extension Education, College of Veterinary

Sciences, Lala Lajput Rai

University of Veterinary and

Animal Sciences, HISAR

(HARYANA) INDIA

Email : anikadhundwal@

gmail.com

See end of the article for

Coopted authors'

\begin{abstract}
The future growth of agricultural production systems (including dairy) is likely to be knowledge intensive. Therefore, a continued support in the form of increasingly improved production technology will prove crucial to achieve higher productivity. Such support is possible only if sustained and focused efforts are made on research and development front. It is only logical to suggest here that a realistic appreciation of the constraints affecting the production systems on part of scientists will be vital to the development of improved technology. Ascertaining the constraint perception of the scientists about the factors affecting the growth of mixed dairy farming systems will be helpful in streamlining the research and development efforts. The study was conducted in Hisar district of Haryana state to document the constraints affecting the growth of mixed dairy farming systems. Thirty scientists working in the College of Veterinary Sciences, Lala Lajpat Rai University of Veterinary and Animal Sciences, Hisar were selected randomly by simple random sampling. Constraints like 'young generation does not like animal husbandry related work', 'non-availability of pasture and fellow land', 'non-availability of green fodder', 'farmers lack of knowledge about improved animal husbandry practices', 'high cost of animal feeds', etc were perceived as most serious by the scientists. On the other hand, items like 'there is perception that animals cause diseases', 'changing milk consumption patterns', 'more time is required for agriculture leaving less for animal husbandry', 'lack of market for dairy products' etc. were perceived as least serious.
\end{abstract}

KEY WORDS...... Constraints affecting growth, Dairying under mixed farming systems

HOW TO CITE THIS ARTICLE - Rachna, Gautam, Malik, Anika and Sangwan, S.S. (2017). Constraints affecting growth of dairying under mixed farming systems : Scientists perception . Asian J. Animal Sci., 12(2): 138-145. DOI : 10.15740/HAS/TAJAS/12.2/138-145.

ARTICLE CHRONICLE - Received : 17.10.2017; Revised : 10.11.2017; Accepted : 23.11.2017 